\title{
A Educomunicação em diálogo com as tecnologias, na educação básica
}

Ismar de Oliveira Soares

Jornalista responsável pela revista Comunicação \& Educação. Assessor Pedagógico da Licenciatura em Educomunicação (CCA-ECA-USP). Presidente da ABPEducom - Associação Brasileira de Pesquisadores e Profissionais da Educomunicação. Membro do conselho diretor da Olcami - Observatório Latino-americano e Caribenho de Alfabetização Midiática e Informacional, com sede no México. Blog <www.abpeducom.org.br>.

E-mail: ismarolive@yahoo.com

Resumo: A Educomunicação apresenta-se como um paradigma, um conceito orientador de caráter sócio-político-educacional a partir da interface Comunicação/Educação. O fato permite e facilita um diálogo permanente entre os que buscam dar respostas às questões vitais anunciadas e descritas nas diretrizes propostas pelo poder público quanto às "experiências escolares" inovadoras e multidisciplinares, previstas na reforma do ensino básico em nosso país. Sendo assim, a primeira parte deste artigo está relacionada às Diretrizes Curriculares Nacionais, tanto para o ensino fundamental quanto para o ensino médio, elaboradas ao longo das últimas duas décadas. A segunda parte é dedicada à apresentação dos artigos e autores presentes na atual edição.

Palavras-chave: educomunicação; educação básica; diretrizes curriculares; comunicação; educação.
Abstract: Educommunication is presented as a paradigm, a guiding concept with sociopolitical and educational nature from the interface between Communication and Education. That allows and facilitates an ongoing dialogue between those who seek to provide answers to vital questions announced and described in the guidelines proposed by the government regarding the innovative and multidisciplinar "school experiences", contemplated in the basic education reform in our country. Thus, the first part of this paper discusses the national curriculum guidelines for both elementary school and high school, carried out over the past two decades. The second part is dedicated to the presentation of papers and authors present in the current issue.

Keywords: educommunication; basic education; curriculum guidelines; communication; education.

Temos afirmado que a Educomunicação apresenta-se, hoje, como um paradigma, um conceito orientador de caráter sociopolítico e educacional a partir da interface Comunicação/Educação. Mais do que como uma metodologia, no âmbito da didática, o neologismo tem sido visto como um parâmetro capaz de mobilizar 
consciências em torno de metas a serem alcanças coletivamente nas diferentes esferas da leitura e da construção do mundo, como propunha Paulo Freire.

$\mathrm{O}$ fato permite e facilita um diálogo permanente entre os que buscam dar respostas tanto às questões vitais anunciadas e descritas nas diretrizes propostas pelo poder público quanto às "experiências escolares" inovadoras e multidisciplinares, previstas na reforma do ensino básico, em nosso país.

Reportamo-nos especialmente às Diretrizes Curriculares Nacionais, tanto para o ensino fundamental quanto para o ensino médio, elaboradas ao longo das últimas duas décadas

\section{ENSINO FUNDAMENTAL: REVERTENDO A LÓGICA DO ORDENAMENTO CURRICULAR}

No caso do ensino fundamental, o diálogo com os educadores pode ser facilitado caso tomemos como referência as Diretrizes Curriculares Nacionais para o ensino de nove anos, aprovadas pelo Conselho Nacional de Educação (CNE), em resolução de 9 de dezembro de 2010². Reportamo-nos especialmente aos elementos identificados como fundamentos indispensáveis para nova proposta, a saber: a "ética", a "política" e a "estética".

No âmbito da ética, o texto das Diretrizes afirma que o ensino fundamental deve ter como referências conceitos como justiça, solidariedade, liberdade e autonomia, o que compreende, entre outras providências, "combater e eliminar quaisquer manifestações de preconceito de origem, raça, sexo, cor, idade e quaisquer outras formas de discriminação". No âmbito da política, a Resolução do CNE aponta para o reconhecimento dos direitos e deveres concernentes à prática da cidadania, entre os quais estão o direito à expressão comunicativa, previsto no Estatuto da Criança e do Adolescente (ECA). Já quanto aos valores estéticos, o documento iguala o cultivo da sensibilidade ao da racionalidade, propondo como objetivo da educação "o enriquecimento das formas de expressão e do exercício da criatividade; de valorização das diferentes manifestações culturais, especialmente as da cultura brasileira; de construção de identidades plurais e solidárias".

É justamente pelo anúncio, por parte do CNE, de que os fundamentos da nova proposta associam ética, política e estética, que o campo transdisciplinar da Educomunicação se sente estimulado a empreender um diálogo permanente com os educadores que têm sob sua responsabilidade a missão de acompanhar as crianças e os adolescentes, em seus processos de descoberta e de construção

do mundo que os rodeia.

Analisamos estes princípios a partir do Parecer CNE/CEB $n^{\circ}$. $11 / 2010$, aprovado em 7 de julho de 2010, de autoria do Conselheiro Cesar Callegari, acessível a partir do portal do MEC/CNE: $<$ http://portal.mec.gov. br/index.php?ttemid $=8$ 66\&id=15074\&option= com_content>.

\section{IDENTIFICANDO O PAPEL DA MÍDIA E DE SUAS TECNOLOGIAS}

Trata-se de um percurso que leva em conta a sociedade da informação e o papel da mídia na geração de conteúdos, mensagens e apelos comportamentais. 
Segundo a justificativa do CNE que embasa o documento, se, de um lado, "é importante a escola valer-se dos recursos midiáticos é, igualmente, fundamental submetê-los aos seus propósitos educativos". Nesse sentido, o texto propõe que valores - presentes muitas vezes de forma conflituosa no convívio social e assim reproduzidos pela mídia - sejam identificados e revisitados pela educação. É o caso, por exemplo, do consumismo e de uma pouco disfarçada indiferença com relação aos desequilíbrios que ocorrem no mundo; indiferença essa que leva, com certa naturalidade, à banalização dos acontecimentos por parte significativa dos meios de informação.

Em relação ao universo da comunicação, a Resolução CNE/CEB n. 7, de 14/12/2010, que estipula as diretrizes para o ensino de nove anos, não permanece, contudo, apenas num denuncismo inócuo. Ao contrário, estabelece metas a serem cumpridas.

É necessário, por exemplo, que a escola contribua para transformar os alunos em consumidores críticos dos produtos midiáticos (meta número 1), ao mesmo tempo em que passem a usar os recursos tecnológicos como instrumentos relevantes no processo de aprendizagem (meta número 2). É dessa criticidade do olhar e da criatividade no uso dos recursos midiáticos que pode surgir uma nova aliança entre o aluno e o professor (meta número 3), favorecida justamente pelo diálogo que a produção cultural na escola é capaz de propiciar.

No caso do docente, o parecer que justificou o documento do CNE entende que "muitas vezes terá que se colocar na situação de aprendiz e buscar junto com os alunos as respostas para as questões suscitadas". Surge, aqui, a meta número 4: reconhecer o aluno como partícipe e corresponsável por sua própria educação, sujeito que é de um direito muito especial: o de expressar-se numa sociedade plural.

\section{EDUCOMUNICAÇÃO NO CURRÍCULO DO ENSINO FUNDAMENTAL}

Retornando ao texto das Diretrizes, verificamos que o MEC propõe que a comunicação não seja apenas objeto de observação e de análise crítica, mas que esteja efetivamente integrada à área de conteúdos, no currículo. Podemos considerar essa como a meta educomunicativa número 5 do programa governamental, que se traduz na inserção da comunicação como eixo transversal a todo o processo educativo.

Vejamos: no Art. $9^{\circ}$, as Diretrizes afirmam que o currículo do ensino fundamental deve ser constituído pelas "experiências escolares" que se desdobram em torno do conhecimento, permeadas pelas relações sociais, buscando articular vivências e saberes dos alunos com os conhecimentos historicamente acumulados e contribuindo para construir as identidades dos estudantes. No caso, a comunicação passa a ser contemplada, levando em conta a convivência dos estudantes com a mídia, por onde "valores, atitudes, sensibilidade e orientações de conduta são veiculados”. 
Para garantir a viabilidade dessas transformações, as Diretrizes reconhecem que "é preciso que se ofereça aos professores formação adequada para o uso das tecnologias da informação e comunicação (esta é a meta de número 6), e que seja assegurada a provisão de recursos midiáticos atualizados e em número suficiente para os alunos" (meta número 7).

Para a formação mais adequada do cidadão brasileiro desde sua infância, as Diretrizes defendem, no Art. 37, a proposta da escola em tempo integral, que terá como objetivo "promover a ampliação de tempos, espaços e oportunidades educativas (meta número 8). Para tanto, os educadores são convidados a compartilhar a tarefa de educar e cuidar com profissionais de outras áreas, as famílias e outros atores sociais”. Tal disposição habilita os sistemas de ensino a contratar outros especialistas com formação universitária e, em especial, com licenciatura voltada para a área específica da Educomunicação (meta número 9).

\section{A EDUCOMUNICAÇÃO NO CORAÇÃO DO PLANO PEDAGÓGICO}

A gestão escolar deve ser "democrática e participativa", dizem as Diretrizes. É o que afirma o Art. 20: "As escolas deverão formular o projeto político-pedagógico, por meio de processos participativos relacionados à gestão democrática".

Essa é, na verdade, a meta 10 , representando a grande novidade do documento. A diferença real, contudo, não está exatamente na presença do conceito "gestão democrática" no texto do MEC, já previsto em legislações anteriores, ao aludirem a um recurso denominado "colegiado" que representaria, para propósitos predefinidos, o exercício compartilhado da administração escolar. O diferencial das Diretrizes vai mais longe, ao deixar clara a disposição de que os alunos devem participar efetivamente do planejamento e da gestão do plano pedagógico das escolas. É o que está previsto no Parágrafo Único do mesmo artigo: "Como sujeito de direitos, o aluno tomará parte ativa na discussão e implementação das normas que regem as formas de relacionamento na escola; igualmente, fornecerá indicações relevantes a respeito do que deve ser trabalhado no currículo e será incentivado a participar das organizações estudantis".

Nada mais explícito, em termos educomunicativos, levando em conta o fato de que qualquer gestão passa necessariamente pelas relações de comunicação! Fica, assim, evidenciado que a comunicação (com seus procedimentos, linguagens e tecnologias) ganha ampla cidadania com as novas Diretrizes, transformando-se em tema central para a área da gestão escolar. Quanto às considerações sobre a aderência da Educomunicação às Diretrizes para o Ensino Médio, remetemos o leitor para nosso livro Educomunicação. o conceito, o profissional e a aplicação. Contribuição para a reforma do Ensino Médio (Paulinas, 2011). 


\section{TECNOLOGIAS NUMA PERSPECTIVA CRÍTICA: ARTIGOS NACIONAIS}

A relação da educação com as tecnologias é retomada na sessão dedicada aos artigos nacionais, em dois textos: "Media literacy, memória e eleições — um experimento sobre como jovens interpretam o apelo à memória na campanha presidencial de 2014", de Roseane Andrelo e Wanessa Bighetti e "O potencial significativo de games na educação: análise do Minecraft", de Luciana Coutinho Pagliarini de Souza e Angelica Caniello.

$\mathrm{O}$ artigo de Andrelo e Bighetti insere-se na área da "Educação para a Comunicação". Tem como pressuposto que saber interpretar as informações disponibilizadas pela mídia é prerrequisito fundamental para compreender as mais diversas engrenagens que movem a sociedade. $\mathrm{O}$ texto relata uma atividade em grupo, em uma escola de Bauru-SP, tendo como foco o uso que os candidatos às eleições majoritárias de 2014 fizeram de diferentes técnicas comunicacionais. Um dos procedimentos foi o resgate do passado histórico, com a avaliação de como jovens eleitores com idade entre 17 e 18 anos interpretam o apelo à memória nas campanhas eleitorais para a presidência.

Já o artigo de Souza e Caniello apresenta reflexões sobre o potencial significativo de games introduzidos no ambiente escolar como prática interdisciplinar. Depois de estudar o Minecraft, o artigo defende, como conclusão, que a inserção de uma linguagem educacional dialógica, lúdica e hipermidiática possibilita que o aluno seja um agente ativo do seu aprendizado, produtor e multiplicador de novos conhecimentos.

\section{MEIO AMBIENTE E CONSUMO}

Os outros dois artigos nacionais voltam-se respectivamente para o tema ambiental ("Comunicação e educação: um contributo para pensar a questão ambiental”, de Adilson Citelli e Sandra Pereira Falcão) e para a questão do consumo ("Consumo e cidadania: em perspectiva a recepção do rap da periferia paulistana", de Fernanda Elouise Budag, Rosilene Moraes Alves Marcelino, Maria Amélia Paiva Abrão e Maria Aparecida Baccega).

Citelli e Falcão analisam a interface Comunicação-Educação como elemento central na construção de sentidos ambientais proativos entre habitantes urbanos. Os achados sinalizam a necessidade de gerar, potencializar e fazer circular/ interpretar, em sistema de retroalimentação, elos que facultem aos moradores de conglomerados humanos refletirem e agirem diante das circunstâncias que reduzam a sua qualidade de vida.

Por seu lado, Budag, Marcelino, Abrão e Baccega procuram, em seu texto, compreender como a cultura midiática e de consumo figuram nas narrativas (letras das músicas) de um grupo de rap da periferia de São Paulo e como são recebidas entre jovens da capital paulista, procurando entender os sentidos de consumo e de cidadania que aí se constituem. 


\section{MÚLTIPLAS LITERACIAS: ARTIGO INTERNACIONAL}

O tema da relação entre Comunicação e Educação tem sido trabalhado, em textos internacionais, sob a designação de "literacias", termo também adotado em Portugal, e que no Brasil se traduz por "alfabetização". É justamente ao conceito de "literacia tecnológica" que se dedica o artigo de Richard Kahn e Douglas Kellner, intitulado "Reconstruindo a tecnoliteracia: uma abordagem de múltiplas literacias". O texto começa com uma breve análise dos significados que "tecnologia" e "literacia" receberam, no sentido de procurar entender a qual tipo de conhecimento e habilidades a "tecnoliteracia" se refere. O foco central do artigo é demonstrar como o esforço internacional sobre a media education vincula-se essencialmente a um projeto democrático de revisão da educação por meio das múltiplas literacias.

\section{GESTÃO DA COMUNICAÇÃO}

Uma escola em que foi implementado o projeto Educom.Radio entre 2001 e 2004, utilizando as práticas educomunicativas como ações de mediações de conflitos baseadas na promoção do diálogo e na aproximação entre os diversos atores sociais presentes no processo educativo, é tema do artigo "Práticas educomunicativas e a redução da violência no contexto escolar", de Marciel Consani e Maria Carolina Aguilera Maccagnini. Mais de dez anos depois do encerramento do projeto, os autores consideraram oportuno analisar a efetividade das ações dos educomunicadores na redução da violência escolar na localidade.

\section{ENTREVISTA}

Cláudia Nonato traz uma entrevista com Sérgio Adorno, coordenador do NEV - Núcleo de Estudos da Violência da USP. Num texto que tem como título "Reflexões sobre a violência e a intolerância na sociedade brasileira". Adorno reflete sobre questões que incomodam a sociedade brasileira: o crescimento exacerbado da violência e da intolerância, em todas as esferas; a ambiguidade dos meios de comunicação nesse processo; a discussão em torno da redução da maioridade penal; e o papel da escola. Para ele, a situação da violência no país é grave e tende a piorar, por falta de planejamento estratégico do Estado.

\section{CRÍTICA}

Em tempos de progressivo amadurecimento da população mundial, o artigo "Precisamos discutir o idadismo na comunicação", de Gisela G.S. Castro, traz uma reflexão sobre a velhice, promovendo um importante debate em torno do idadismo, uma forma de preconceito, baseado na idade, que ocasiona a discriminação contra as pessoas vistas como idosas e contribui para a sua marginalização 
e eventual exclusão social. Além disso, a autora discute o preconceito motivado pelos estereótipos associados à figura do velho em nosso meio social.

\section{DEPOIMENTO E EXPERIÊNCIA}

A revista traz a história de vida da ativista Conceição Oliveira, cuja experiência com livros didáticos rendeu-lhe dois Prêmios Jabutis, na categoria "Didático e Paradidático Ensino Fundamental e Médio", com as coleções "Paratodos-História” (Editora Scipione), em 2005, e "História em Projetos” (Editora Ática), em 2008. Já a seção Experiência traz o relato educomunicativo de Maria do Carmo Souza de Almeida, trabalhando com o cinema em duas Licenciaturas da Universidade de Taubaté.

\section{POESIA}

O professor Arlindo Rebechi Junior, da Unesp, nos apresenta Augusto de Campos. Nascido em São Paulo, em 1931, o poeta, tradutor, ensaísta, crítico de literatura e música é um dos principais nomes da poesia concreta brasileira. Segundo o autor do artigo, "sua trajetória intelectual esteve sempre envolta à poesia, embora não exclusivamente a ela. Exímio tradutor, junto com seu irmão, Haroldo de Campos, foram responsáveis por trazer, ao público brasileiro, grandes autores de diferentes épocas da literatura mundial”.

\section{RESENHAS}

São apresentadas as seguintes produções:

- "Relações de gênero na ficção televisiva ibero-americana", de Fernanda Castilho realizando uma síntese dos principais pontos abordados no Anuário Obitel 2015 - "Relações de Gênero na Ficção Televisiva", coordenado por Maria Immacolata Vassallo de Lopes e Guillermo Orozco Gómez.

- "Entre palavras e imagens. Onde fica mesmo o índio na fundação do Brasil?”, de Maria Ignes Carlos Magno. A proposta dessa resenha é discutir a partir dos filmes: Palavra e utopia, do cineasta Manoel de Oliveira e Anchieta, José do Brasil, de Paulo César Saraceni, as complexas relações entre os colonizadores e os indígenas do Brasil.

- "O piloto-aprendiz e o engenheiro-mestre: O ensino esportivo do automobilismo em Dias de trovão e Carros”, de Rafael Venâncio. A proposta é de apresentar dois filmes que relatam o ensino do automobilismo através da relação entre um mestre e um aprendiz, sendo o primeiro um filme blockbuster (Dias de trovão, 1990, de Tony Scott) e outro, uma animação focada no público infantil (Carros, 2006, de John Lasseter). 
comunicação \& educação • Ano XX • número 2 • jul/dez 2015

\section{ATIVIDADES EM SALA DE AULA}

Como já é tradição há mais de 15 anos na revista Comunicação Ẽ Educação, Ruth Ribas Itacarambi traz valiosas sugestões de projetos a serem desenvolvidos por professores em sala de aula, a partir dos artigos da revista. 